\title{
Concepts in sperm heterogeneity, sperm selection and sperm competition as biological foundations for laboratory tests of semen quality
}

\author{
William V Holt and Katrien J W Van Look \\ Institute of Zoology, Zoological Society of London, Regent's Park, London NW1 4RY, UK \\ Correspondence should be addressed to WV Holt; Email: Bill.holt@ioz.ac.uk
}

\begin{abstract}
Stringent selection mechanisms, in both internal and external fertilisation systems, reject all but a significant minority of the spermatozoa released at ejaculation. Sperm competition theory provides circumstantial evidence that the selection process involves mechanisms by which the quality of the fertilising spermatozoon is controlled, thereby ensuring that females and their offspring receive high quality genetic material. In this review we examine some of these selection processes to see whether they could be exploited for the improvement of laboratory tests of sperm quality. Such tests are not only required for clinical and agricultural purposes, but are increasingly needed in fields such as reproductive and environmental toxicology where the species requirement is much broader. Despite many years of research, sperm quality assessment methods continue to provide imprecise data about fertility; here we suggest that this may be a consequence of using tests that focus on the spermatozoa that would normally be unable to fertilise under natural conditions.

To achieve fertilisation a spermatozoon must be capable of responding appropriately to external signalling stimuli; those involving protein kinase-regulated flagellar function seem especially influential in governing effects ranging from non-Mendelian inheritance in mammals to sperm chemotaxis in sea urchins. Examination of the elicited responses reveals considerable heterogeneity in all species. Here we propose that this level of heterogeneity is meaningful both in terms of understanding how spermatozoa from some individuals possess fertility advantages over spermatozoa from their rivals in sperm competition, and in that the heterogeneity should be exploitable in the development of more accurate laboratory tests.

Reproduction (2004) 127 527-535
\end{abstract}

\section{Introduction}

The ubiquitous occurrence of sperm selection mechanisms throughout nature, some depending upon the selfselective propensities of spermatozoa while others involve antagonistic selection imposed by the female reproductive system, has stimulated considerable theoretical interest and debate for many years. Evolutionary biologists have developed several hypotheses that link sperm selection to the inheritance of superior fitness traits (i.e. disease resistance, offspring survival and fecundity); however, recognising the properties of the selected spermatozoa would also provide valuable insights required for the development of useful semen quality tests, which, despite many years of development, still remain elusive. In this review we examine the value of sperm function tests in the context of the biological issues involved to see how much guidance can be gleaned from the natural selection processes.

\section{Current needs for sperm assessment technology}

Semen assessment methods are used extensively in investigations of human clinical infertility and the last decade has seen the introduction into andrology laboratories of computer-assisted methods for both sperm motility and morphology analyses. Efforts to develop and maintain high and consistent diagnostic standards have led to the introduction of national quality control schemes and nationally organised courses for andrology technicians. Pig and cattle farmers routinely obtain semen for artificial insemination from national and international breeding companies, whose primary goal is to develop and supply semen from boars and bulls of high genetic merit. These companies are aware that they must maintain high standards of product, and therefore subject the semen to rigorous quality control procedures. Some use computerised methods for sperm evaluation, thus obtaining information about the quality of overall motility and morphology, and 
others couple this with tests to evaluate sperm plasma membrane and acrosomal integrity. The instrumentation used for analysing these tests varies, from subjective microscopic examinations to the use of computer-assisted sperm motility analysis or flow cytometry in conjunction with specific fluorescent probes. The primary objectives of the clinical and agricultural andrologists relate to the question 'how fertile is this sample?' Unfortunately, a precise prediction of fertility cannot be provided, although it is probably true that problematic samples can usually be distinguished.

However, semen assessment methods are not the exclusive province of clinical and veterinary andrologists. Fertility effects of new pharmaceuticals must be evaluated, typically in mice, rats and primates, as part of the national and international approval process. At present, the resultant data remain imprecise. Researchers who investigate male reproductive physiology also use a wide variety of sperm evaluation procedures, depending upon context. Typical examples of current interest might involve evaluating sperm quality and fertility after manipulation of spermatogenesis through transgenic and gene knockout treatments, or through experimental exposure to endocrine-disrupting chemicals. The latter experiments are frequently undertaken using a variety of model organisms, including several species of small and rapidly breeding fishes, such as zebrafish and fathead minnow. Fish sperm assessment is also needed in aquaculture research where semen cryopreservation technology is widely used. Currently there is also considerable academic interest in explaining aspects of evolutionary biology through the influence of sperm competition; this body of literature refers to an array of species from several taxonomic groups, especially mammals, birds, fishes and insects. These studies attempt to identify factors that explain why one apparently normal and fertile semen sample is, in fact, more capable of fertilising eggs than another. Few of the semen tests that are currently available are able to provide mechanistic explanations for these phenomena. This particular observation strongly suggests that much useful information about fertility may be gained by looking at whether the spermatozoa that actually achieve fertilisation under these conditions can be distinguished from those that do not.

\section{Fertilisation, sperm quality and selection}

Although it might seem that spermatozoa only have to fulfil a single role, namely to achieve syngamy, this can only occur if multiple cell functions operate flawlessly and synchronously during the events preceding, during and after fertilisation. Inherent failure of any of the crucial cell systems within an individual spermatozoon will prevent it from fertilising the oocyte and supporting subsequent embryonic development. Fertilisations nevertheless continue to occur despite the drawbacks, and the process is of universal importance for the continuation of life on this planet. It is relevant to this review that the spermatozoa that eventually reach and fuse with oocytes under natural conditions have almost invariably been subjected to stringent selection. If the selection mechanisms that operate in nature are able to discriminate the quality of spermatozoa, understanding the basis of the naturally imposed selection mechanisms may help to clarify which of the many laboratory tests are likely to be most informative about fertility. We therefore begin by briefly reviewing some of the current hypotheses about sperm selection.

The last three decades have witnessed the development of a body of theory about sperm competition, which is said to occur when spermatozoa from more than one male have the opportunity to fertilise eggs from a single female during the same fertile period (for reviews see Parker 1970, 1998). Sperm competition thus occurs when several males mate with a polyandrous female. In this situation, the male who can produce the most and best-quality spermatozoa has an advantage over his rivals, and several studies have demonstrated that large testes size, hence a greater sperm production capacity, is a feature of species which exhibit multimale mating systems (see, for example, Harcourt et al. 1981). Social dominance is also a determinant in such mating systems, as age, body weight and behavioural differences influence the relative number of spermatozoa contributed by each of the males.

A number of classic experimental studies of sperm competition have, however, established that paternity is still skewed even if confounding factors such as sperm numbers and insemination timing are eliminated (for review see Dziuk 1996). Elegant heterospermic insemination (HI) experiments with bull, rabbit and pig spermatozoa, where equal numbers of spermatozoa from two or more males are mixed and inseminated in equal proportions, have shown that spermatozoa from individual males can be ranked in order of fertilisation efficacy (Beatty et al. 1969, Stewart et al. 1974, Parrish \& Foote 1985, Berger et al. 1996). Such observations strongly suggest that some aspects of sperm quality per se determine fertilisation success. In this context the meaning of the term 'sperm quality' remains unclear and controversial, but implies (i) the existence of a positive correlation between sperm phenotypes and the fitness of the offspring that derives from that particular spermatozoon, or (ii) that some spermatozoa simply possess a 'fertilisation advantage' over others. The first alternative would seem more satisfactory from an evolutionary point of view as it suggests a mechanism for the natural selection of fitness traits (Birkhead \& Pizzari 2002).

Evidence from genetic studies of natural mating strategies and their outcomes seems to support this view. Paternity identification techniques have revealed previously unsuspected levels of extra-pair paternity across many species. Several hypotheses have been developed that attempt to explain the evolutionary benefits that females may derive from such high levels of polyandry (Zeh \& Zeh 2001) and sperm competition (Keller \& Reeve 1995), most 
of which are highly relevant to issues of sperm quality assessment. A few of the suggested hypotheses and their proposed biological benefits are noted in Table 1. Some authors consider that females can somehow assess the genetic quality of spermatozoa from different males and choose those (the 'good' sperm or 'good' genes) that will confer genetic benefits to their offspring (Yasui 1997). Others have pointed out that females could 'choose' spermatozoa with immunologically compatible characteristics (Zeh \& Zeh 2001), perhaps based on the major histocompatibility antigen they express. For species with internal fertilisation, these and other hypotheses would imply the existence of subtle but efficient sperm selection mechanisms in the female reproductive tract. As the nuclear genome contained within the sperm head is highly condensed and inaccessible, it is implausible to infer that a DNA-scanning mechanism exists allowing the female reproductive tract to choose between males or between different spermatozoa. The hypotheses linking sperm quality with offspring quality therefore infer another hypothesis, namely that linkage exists between aspects of sperm phenotype and genotype. A number of authors have supported this proposal, especially in terms of sexual selection and antagonism, where the female reproductive tract is considered to undergo evolutionary changes that tend to impede sperm transport, while spermatozoa are under evolutionary counter pressure to overcome these obstacles (Roldan \& Gomendio 1999). Pizzari \& Birkhead (2002), who recently reviewed this literature, considered that sperm function is influenced by 'fertilisation efficiency genes', which provide fertility advantages when needed. This differs subtly from the cryptic female choice models, since there is no overt necessity that fertilisation efficiency correlate with offspring quality.

Ultimately, it is important that gamete fusion involves only one spermatozoon per oocyte. Species with internal fertilisation mechanisms achieve this state by ensuring that the oocyte interacts in vivo with very low sperm numbers at any given moment, while fishes with external fertilisation use a specialised channel, the micropyle, to limit sperm entry. In either system the chosen spermatozoon is the end product of a stringent selection process and, by definition, it must possess all of the attributes that make it fertile. The egg, or the female reproductive tract, has probably not had the opportunity to assess its DNA quality directly, and thus selection has been based on sperm phenotype and function. Evolutionary adaptation has, however, allowed a few species to adopt a different way of ensuring that only one spermatozoon is involved in fertilisation, by use of a process that does indeed appear to involve DNA quality assessment. Urodele amphibians (for example, newt and axolotl) allow several spermatozoa to fuse with a single egg; these then all undergo nuclear decondensation to form pronuclei, generate asters and synthesise DNA (Wakimoto 1979). One of the sperm pronuclei then fuses with the female pronucleus, whereupon the accessory sperm pronuclei degenerate. Interestingly, before syngamy is finally achieved, the female pronucleus executes a complex series of excursions within the egg cytoplasm, which involves 'visiting' the various male pronuclei and possibly indulging in some kind of selection process.

\section{What mechanisms may be responsible for sperm selection?}

Any mechanisms for sperm selection must, by definition, operate on heterogeneous cell populations, and spermatozoa within any ejaculate exhibit considerable heterogeneity in many different respects. Obvious abnormalities such as acrosomal absence and flagellar deformity, which cause clinical infertility in humans and other species, will disqualify spermatozoa from taking part in fertilisation. In

Table 1 Some hypotheses explaining the existence and function of sperm competition and cryptic female choice of spermatozoa. (The term 'cryptic female choice of spermatozoa' refers to the post-copulatory preferential choice of spermatozoa from one male rather than another within the female reproductive tract.)

\begin{tabular}{|c|c|c|}
\hline Hypothesis & Proposed benefit to female & References \\
\hline $\begin{array}{l}\text { The 'Intrinsic male } \\
\text { quality' hypothesis }\end{array}$ & $\begin{array}{l}\text { Sperm competition or cryptic female choice } \\
\text { of spermatozoon increases the probability of } \\
\text { fertilisation by a high quality spermatozoon or male }\end{array}$ & $\begin{array}{l}\text { Watson (1991), Madsen et al. (1992), } \\
\text { Birkhead et al. (1993) }\end{array}$ \\
\hline The 'Trading-up' hypothesis & $\begin{array}{l}\text { In a socially monogamous pair context, the extra-pair } \\
\text { copulations compensate for a poor quality mate }\end{array}$ & $\begin{array}{l}\text { Kempenaers et al. (1992), Hasselquist et al. } \\
\text { (1996), Petrie \& Kempenaers (1998) }\end{array}$ \\
\hline The 'Bet-hedging' hypothesis & $\begin{array}{l}\text { Polyandry enables females to guard against mate } \\
\text { choice errors }\end{array}$ & Watson $(1991,1998)$ \\
\hline $\begin{array}{l}\text { The 'Sexually-selected } \\
\text { sperm' hypothesis }\end{array}$ & $\begin{array}{l}\text { The sons of multiply-mated females produce } \\
\text { competitively superior spermatozoa or ejaculates }\end{array}$ & $\begin{array}{l}\text { Harvey \& Bennett (1985), Keller \& Reeve (1995), } \\
\text { Pizzari \& Birkhead (2002) }\end{array}$ \\
\hline $\begin{array}{l}\text { The 'Offspring diversity' } \\
\text { hypothesis }\end{array}$ & $\begin{array}{l}\text { Higher offspring genetic variability enhances female } \\
\text { fitness by reducing sibling competition or by serving } \\
\text { as a hedge against environmental uncertainty }\end{array}$ & Ridley (1993) \\
\hline $\begin{array}{l}\text { The 'Genetic incompatibility } \\
\text { avoidance' hypothesis }\end{array}$ & $\begin{array}{l}\text { Females minimise risks associated with immunological } \\
\text { feto-maternal incompatibility or maternal vs paternal } \\
\text { genomic conflict }\end{array}$ & Zeh \& Zeh (2001) \\
\hline $\begin{array}{l}\text { The 'Good sperm' or } \\
\text { 'Good genes' hypothesis }\end{array}$ & $\begin{array}{l}\text { Females ensure their eggs are fertilised by the best } \\
\text { sperm, so that offspring fitness is maximised }\end{array}$ & Curtsinger (1991), Yasui (1997) \\
\hline
\end{tabular}


the present context, we regard such clinical abnormalities as exceptions and concentrate upon looking for clues about more subtle types of heterogeneity.

\section{Sperm motility}

Motility is a common feature of spermatozoa throughout the animal kingdom. In aquatic species with external fertilisation the spermatozoa are released into a hostile environment where they typically become activated then survive for a short period; only 1 or $2 \mathrm{~min}$ in the case of freshwater fishes. Their encounter with eggs is a matter of probability, many spermatozoa never reaching them at all. Of those that reach the egg only one enters through the micropyle, an opening that permits sperm entry for a brief period (less than 2 min; Linhart et al. 1995). Sperm selection thus operates at several levels in typical external fertilisation systems, the first priority for spermatozoa being the need to reach an oocyte. The presence of numerous spermatozoa in the ejaculate helps with this initial process, and sperm motility (flagellar beat frequency, velocity and flagellar wave morphology) allows the ejaculate to occupy as much water volume as possible, thus increasing the probability of sperm-egg interactions. Sperm longevity after activation also influences fertilising ability. Superior ability to withstand the osmotic stresses of exposure to hypotonic (freshwater) or hypertonic (seawater) environments confers a selective advantage upon spermatozoa and is recognised as determining relative fertility in fishes. Alternative mating tactics and sperm competition mechanisms in fishes have undergone elaborate evolution (for reviews see Stockley et al. 1997, Taborsky 1998), much of it being directed towards producing large sperm numbers and being able to deposit them in the most favourable sites.

More subtle sperm selection occurring near the egg surface involves cell signalling systems: (i) sperm-activating peptides produced by the egg jelly coat of sea urchin eggs, speract and resact, induce sperm chemotaxis (Ward et al. 1985, Cook et al. 1994). Recently Wood et al. (2003) have shown that these peptides induce calcium fluctuations in the flagellum, thereby controlling the vigour and nature of sperm motility; (ii) Yu et al. (2002) have recently shown that trout spermatozoa adhere to the peri-micropylar region of the egg surface through specific cell-cell carbohydrate interactions; these activate protein kinase-related signal transduction mechanisms within the sperm head; and (iii) Iwamatsu et al. (1997) found that linear swimming velocity is correlated with the ability of spermatozoa to enter the micropyle, a finding which relates to observations by Creech et al. (1998) that fish sperm velocity increases under the influence of the signalling molecule, nitric oxide, produced by the eggs around the site of sperm entry. In their paper Wood et al. (2003) commented that sea urchin sperm populations are heterogeneous in their response to speract; one subpopulation within the sample of spermatozoa was unable to respond because the calcium concentrations were already high.
Fertilisation success would depend significantly upon the relative size of the unresponsive subpopulation.

For species with internal fertilisation, motility is important for sperm transport within the reproductive tract and for egg penetration. Important clues about the relevance of sperm motility to mammalian fertility have come from a series of papers (especially in relation to the t-haplotype mouse; Olds-Clarke \& Johnson 1993) about transmission ratio distortion (TRD). This is an effect whereby genetic mosaicism resulting from meiotic recombination during spermatogenesis leads to the development of genetically distinct sperm subpopulations that are either functionally advantaged or disadvantaged with respect to flagellar activity. While spermatozoa with normal flagellar activity are able to cross the utero-tubal junction and enter the oviduct, those spermatozoa with abnormal flagellar function are unable to do so. Mechanistically, TRD in the case of the t-haplotype occurs because the cell signalling cascades that control flagellar function and motility operate incorrectly. The protein kinases controlling flagellar function in these mice are overexpressed and cause abnormal sperm motility; however, those spermatozoa carrying the $t$-haplotype also possess a $t$-complex responder gene $\left(\mathrm{T}_{\mathrm{cr}}\right)$, which corrects the overexpression of the sperm motility kinase gene $(s m o k)$, and restores normal flagellar action (Herrmann et al. 1999). During meiosis the $\mathrm{T}_{\mathrm{cr}}$ co-segregates with the Y-chromosome and causes 95\% skewing of the offspring sex ratio in favour of males by promoting unbalanced fertilisation success. This extreme example, which results in non-Mendelian inheritance, is paralleled by non-Mendelian transmission of retinoblastoma in humans (Girardet et al. 2000); TRD, due to defects in sperm motility, has also been detected in transgenic mouse strains carrying a thymidine kinase reporter gene or a gene for angiotensin-converting enzyme (Hagaman et al. 1998).

These data, from what can be viewed as natural sperm competition experiments, provide an intriguing insight into possible mechanisms of sperm selection. They indicate how genetic traits, not overtly reproductive in nature, can be influenced directly by their association with protein kinase-regulated signalling cascades that affect sperm motility. Reproductive skews detected in $\mathrm{HI}$ experiments may therefore be partly attributable to similar mechanisms. This suggestion is supported by observations that when porcine sperm populations are activated by bicarbonate (Tajima et al. 1987), a stimulator of adenylyl cyclase and also indirectly of protein kinase A, heterogeneous responses are seen both within single semen samples and between individual boars (Harrison \& Holt 2000, Holt \& Harrison 2002) (Fig. 1). Subpopulations of boar spermatozoa respond to bicarbonate in different ways; some are quiescent in the absence of bicarbonate but are rapidly stimulated to maximal progressive motility, some are refractory to stimulation, and others lie somewhere in between. From these observations we hypothesise that when ejaculates from two or more boars are 

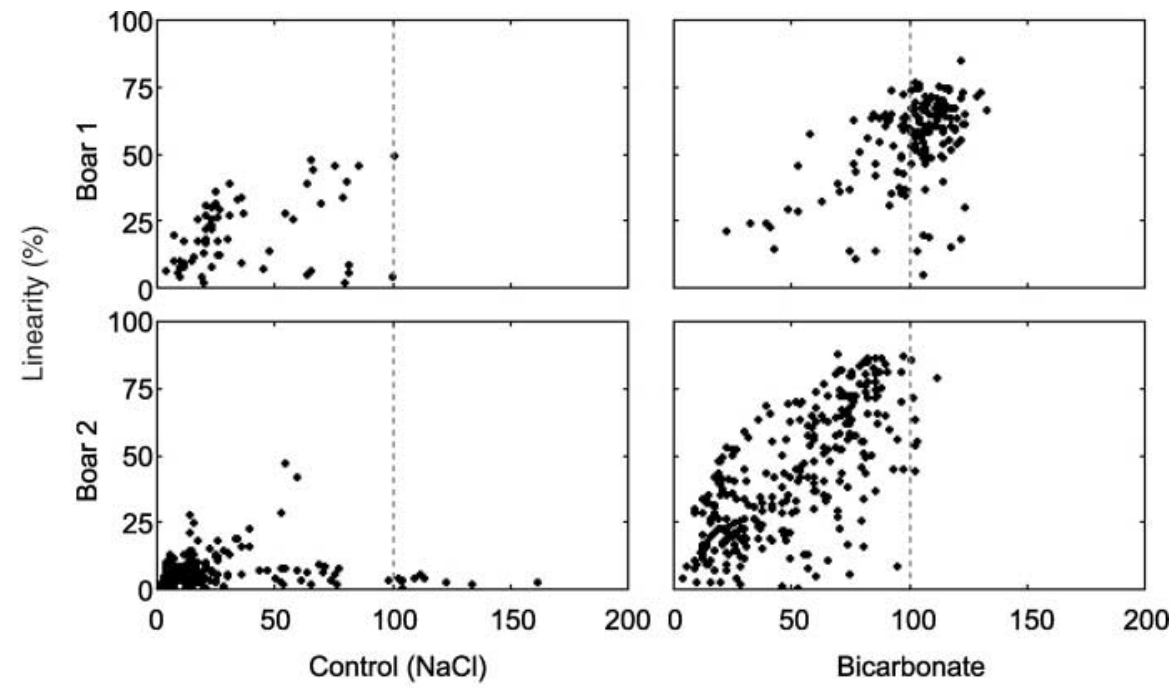

Average Path Velocity $\left(\mu \mathrm{ms}^{-1}\right)$

Figure 1 Bicarbonate-induced motility stimulation in boar spermatozoa. Washed spermatozoa from two different boars were incubated at $38^{\circ} \mathrm{C}$ in a bicarbonate-free Hepes-buffered Tyrode's-based medium. After $10 \mathrm{~min}$ incubation, $15 \mathrm{mM}$ bicarbonate/5\% $\mathrm{CO}_{2}$ was added to one half of the sample while the other half received $15 \mathrm{mM} \mathrm{NaCl}$ (as control treatments). Sperm samples were video-recorded and their motion analysed using a Hobson sperm tracker. Left hand panels show that in the absence of bicarbonate, most spermatozoa (points represent individual spermatozoa) moved slowly and non-linearly (low linearity and average path velocity), but 2 min after bicarbonate addition (right hand panels) most spermatozoa exhibited significantly increased linearity and velocity. However, while the velocities of most spermatozoa from boar 1 cluster above $100 \mu \mathrm{ms}^{-1}$ (vertical line), most of those from boar 2 remain below this threshold (for more detailed protocols see Abaigar et al. 2001, Holt \& Harrison 2002). Such differential stimulation may be significant in sperm selection mechanisms.

mixed within the female reproductive tract, and exposed to naturally occurring bicarbonate, the relative proportions of the most active sperm subpopulations would differ, and the ejaculates with the highest proportion of activated spermatozoa would be advantaged in terms of fertility. This would undoubtedly skew the relative numbers of spermatozoa colonising the oviduct, even if the relative numbers of spermatozoa initially inseminated were the same. The hypothesis is supported by findings that reproductive advantage in $\mathrm{HI}$ experiments with boars is correlated with the numbers of accessory spermatozoa attached to the zona pellucida (Stahlberg et al. 2000); these findings indicate that fertilisation advantage occurs as a result of preferential ability to reach the site of fertilisation, the oviduct. Some evidence that selective breeding for high fertility boars in breeding centres is associated with a greater tendency for bicarbonate-induced sperm activation also supports this hypothesis (Abaigar et al. 1999).

This consideration of sperm motility and its significance may explain why simple measures of motility based on parameters like sperm average path velocity, or estimates of the proportion of motile spermatozoa in a sample, remain poor predictors of fertility under competitive conditions. In this context the application of sophisticated methods of motility evaluation will remain uninformative unless more account is taken of population heterogeneity. In similar vein, a number of authors have investigated the significance of flagellar length, based on the presumption that flagellar length is directly correlated with velocity (Gomendio \& Roldan 1991). This approach is naive as it ignores the existence of biochemical activation and switching mechanisms, and therefore it is not surprising that little evidence for a relationship between flagellar length and fertility has yet been found.

\section{Capacitation, egg recognition and penetration}

In many species with internal fertilisation, spermatozoa do not immediately proceed towards the egg surface, but undergo a period of storage within the female reproductive tract. Storage time can vary from a few hours or days to several years, depending on the species (for comparative data on sperm storage see Birkhead \& Moller 1993). The mechanisms of interaction between spermatozoa and the female reproductive tract are of considerable interest, partly because of the potential for understanding the way in which the female reproductive tract maintains sperm viability over such prolonged periods (for review see Hunter \& Rodriguez-Martinez 2004). At present there are several indications that sperm storage involves selection, including the observation that the mammalian oviduct preferentially stores uncapacitated spermatozoa (Smith \& Yanagimachi 1991, Fazeli et al. 1999). In mammals, capacitation is a complex physiological process that involves biochemical, biophysical and metabolic modifications of all parts of the spermatozoon. It results in altered plasma membrane architecture and permeability, modulates flagellar activity and leads to hyperactivation, a state in 
which spermatozoa exhibit vigorous and high amplitude flagellar beating that is thought to assist penetration through the zona pellucida. One interesting consequence of capacitation is the apparent activation, or unmasking, of receptors that respond to chemical stimuli from oocytes or thermal gradients within the oviduct (Fabro et al. 2002, Bahat et al. 2003). Once the sperm reservoir has been established in the oviduct, only a small proportion of spermatozoa undergo capacitation at any given period. These spermatozoa, which at that point represent a selected population from the original ejaculate, are therefore subjected to further stringent selection; in mammals only about $10 \%$ of the capacitated spermatozoa are responsive to these chemotactic or thermotactic signals (Eisenbach 1999), and they remain responsive for a limited period. Although the details of this process are unknown it is clear that this provides yet another potential mechanism, possibly involving sperm membrane olfactory receptors, whereby spermatozoa from different males could compete for access to the oocyte.

A similar situation exists in aquatic species with external fertilisation where selectivity not only involves discrimination between spermatozoa of the same species, but also involves species specificity. Swanson \& Vacquier (2002) recently published a comprehensive review showing that reproductive proteins involved in gamete interactions, particularly, but not exclusively, among aquatic species, undergo unusually rapid evolution driven by sexual antagonism and the constant need for sperm selection. One example of a sophisticated mechanism for cryptic female choice and sexual selection occurs in the sea urchin, Echinometra, where one egg prefers to bind a spermatozoon carrying a particular allele of the sperm-surface protein, bindin, while other eggs have little affinity for the same sperm type (Palumbi 1999).

\section{Sperm selection, fertilisation and embryo development}

It is evident from the above discussion that the concept of 'fertilisation efficiency genes' (Pizzari \& Birkhead 2002) is deceptively complex. Whether their environment is the female reproductive tract or water, spermatozoa are subjected to multiple selective processes that ultimately accept few of their number. This process is thought to have resulted in an unusually rapid evolutionary rate among the proteins involved in these processes, regardless of species or taxon. Because multiple steps are required to achieve fertilisation, variability and meiotic assortment among relevant reproductive genes, they provide limitless ways to affect sperm function. The huge numbers of spermatozoa produced by spermatogenesis represent the results of such recombinations, as though males must strive to cover every likely eventuality of the selective process.

The need to produce large numbers of spermatozoa has been regarded as a compensatory mechanism for inevitable errors of DNA replication during spermatogenesis
(Cohen 1969). While this seems an attractive and logical hypothesis, advances in methods of DNA assessment do not provide much direct support. There has been a recent upsurge of clinical interest in assessing the quality of sperm DNA and chromatin structure in relation to human infertility, looking especially at aspects such as DNA fragmentation and the occurrence of strand breakage. Several methods of assessing DNA in individual spermatozoa have been developed, which demonstrate the existence of an inverse correlation between defective DNA structure and embryonic survival in humans (see Larson-Cook et al. 2003 and references therein). Although these tests are highly predictive of negative pregnancy outcome in humans, several studies have shown that they are uncorrelated with fertilisation rate. This discrepancy is important within the context of the present discussion because it means that the selection processes for human fertilisation do not screen for the physical quality of DNA. Studies aimed at investigating the effects of cryopreservation in fish (loach, Misgurnus fossilis) spermatozoa (Kopeika et al. 2003) produced data that parallel the human studies. In these experiments, embryonic mortality was significantly increased when cryopreserved, compared with fresh, spermatozoa were used to fertilise eggs. Fertilisation rate was effectively removed as a variable in these experiments by discarding all unfertilised eggs and only monitoring the development of those that had fertilised normally. As cryopreservation is an unnatural process that may physically damage DNA integrity, it is not surprising to find that natural selection systems cannot detect its effects. Similarly, human clinical infertility may often be caused by unnatural factors such as cigarette smoking (Fraga et al. 1996) and anticancer drug treatment.

\section{Conclusions; implications for sperm quality assessment}

The foregoing discussion has drawn attention to the complexity of natural sperm selection mechanisms, and has also emphasised that, despite the normally large numbers of spermatozoa in an ejaculate, only a minority are able to meet the stringent requirements needed to fertilise an egg. Does this mean that sperm quality assessment methods in the laboratory would improve if they could incorporate aspects of these selective processes? The logical answer seems to be affirmative, but at present there are still insufficient data to support this view. For example, evidence about the importance of motility-related kinases can be drawn from a variety of species, both vertebrates and invertebrates. Under natural conditions these kinases significantly impact upon the success of fertilisation; however, to the best of our knowledge there are no laboratory tests that incorporate such factors. Equally, there are no data that confirm, for example, that conception rates in pigs, mice or humans are correlated with sperm protein kinase A activity at artificial insemination. There is also an 
emerging set of data about chemotaxis and sperm plasma membrane receptors, also in vertebrates and invertebrates, that provides strong indications that a subset of spermatozoa possess the requisite receptors and signalling systems to allow them to respond appropriately to these signals. However, this is still a subject for academic study that needs further investigation.

The foregoing discussion has argued that sperm selection is a powerful and universally important process, and that the fertilising spermatozoa are almost invariably subject to various selective processes prior to, during and, occasionally even after, the union of eggs and spermatozoa. Laboratory-based semen quality assessment methods may therefore be most informative when a degree of sperm selection is incorporated. This assertion is supported by studies of sperm penetration through cervical mucus (Aitken et al. 1992, Cox et al. 2002), and therefore the inclusion of a cervical mucus penetration test in the World Health Organisation's semen assessment manual (WHO 1992) makes considerable sense. Combining sperm selection protocols with other assays, for example acrosomal integrity and morphology, may also increase the effectiveness of tests. Species with external fertilisation would, however, not be amenable to the same simple sperm selection procedures.

In addition to the use of semen assessment tests for estimating fertility, there is an increasing trend towards the use of spermatozoa as response indicators for pharmacological or toxicological tests. In some cases whole animals are subjected to treatments and their spermatozoa are subsequently tested, while in other scenarios the spermatozoa themselves are tested after in vitro exposure to various compounds. Nuclear DNA may be deleteriously affected during spermatogenesis under the treatment regimes used, and therefore there is considerable merit in using tests, such as 'TUNEL' or 'Comet' assays for the detection and quantification of DNA strand breakage, that examine the sperm nuclear DNA directly. These could also be combined with sperm selection tests. However, computer-assisted sperm motility measurements are also increasingly used because the spermatozoa are sensitive to environmental conditions (Kime et al. 2001). Sperm motility is suppressed in the presence of low concentrations of toxic chemicals such as heavy metals, but as shown in Fig. 2 the responses also reveal the heterogeneity typical of sperm populations. By developing appropriate statistical methods for the analysis of such heterogeneity, bearing in mind that motility is short-lived and undergoes transient changes, it may be possible to increase considerably the sensitivity of such tests by abandoning the approach whereby all sperm responses are measured and averaged.

Gaining an understanding that a minority of spermatozoa are the functionally significant population should, in theory, provide a warning that most spermatozoa are somehow functionally flawed. Harrison (1998) discussed the practical implications of this observation in relation to mammalian in vitro fertilisation (IVF) technology. Based on his own and the research experiences of others with porcine IVF systems he estimated that the number of
Goldfish 4

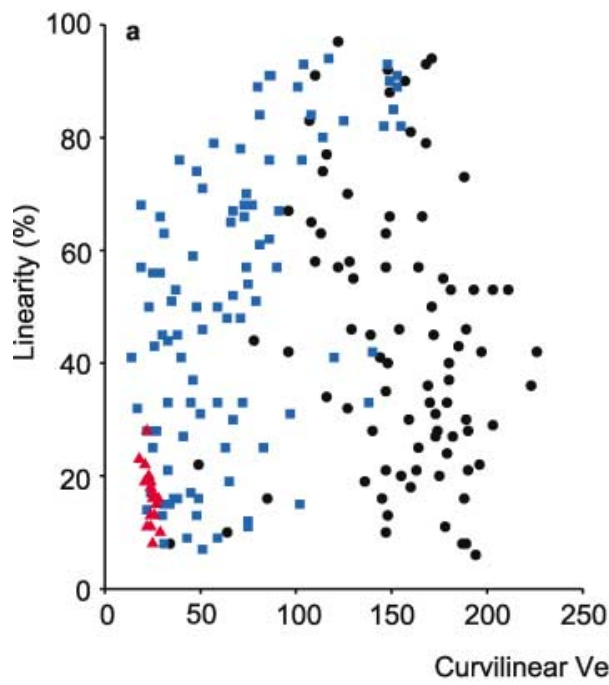

Goldfish 6

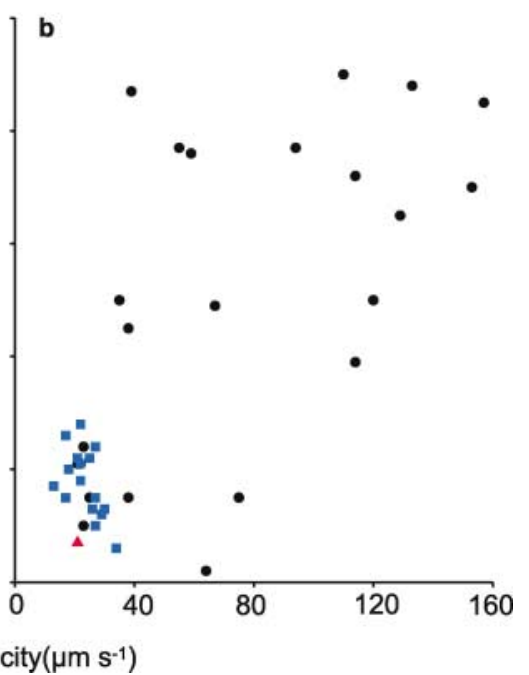

Figure 2 In vitro mercuric chloride-exposed goldfish sperm. Milt was diluted in goldfish extender containing mercuric chloride and kept at $4{ }^{\circ} \mathrm{C}$ for $24 \mathrm{~h}$. After $24 \mathrm{~h}$, sperm were activated in water and motility analysed using computer-assisted sperm analysis on a Hobson sperm tracker (for more detailed method see Van Look \& Kime 2003), points represent individual spermatozoa. (a) Mercuric chloride $\left(0.1 \mathrm{mgl}^{-1}\right.$ (blue squares)) exposure to sperm of goldfish 4 caused the sperm to swim more slowly than control sperm (black circles), but track linearities and velocities were heterogeneous in both samples. The higher mercuric chloride dose $\left(1 \mathrm{mgl}^{-1}\right.$ (red triangles)) caused significant suppression of both velocity and linearity. (b) Spermatozoa from goldfish 6 were more sensitive to mercuric chloride; both doses of mercuric chloride $\left(0.1 \mathrm{mgl}^{-1}\right.$ (blue squares) and $1 \mathrm{mgl}^{-1}$ (red triangles)) significantly suppressed velocity and caused the spermatozoa to move with more circular paths than the control sperm (black circles). 
competent spermatozoa in an IVF culture dish (i.e. an unselected population) might be as low as $0.036 \%$, with the maximum estimate only rising to $0.88 \%$. In these circumstances the gross estimates of sperm population parameters that are in common usage would only provide overwhelming data about ineffective spermatozoa. There is therefore considerable merit in attempting to concentrate on the significant subpopulations, but improvements in laboratory test methods have typically concentrated on refining the technology rather than considering the significance of the data. Using the data in Figs 1 and 2 as examples, while it is clear that computer-assisted semen analysis technology can provide sophisticated data about sperm parameters, their significance is best appreciated if the behaviour of individual spermatozoa is considered. Aggregating the data as simple means and variances hides much of the significant information.

A common conclusion that emerges from the literature is that, surprisingly, most spermatozoa are not capable of fertilisation. The biological issues behind this phenomenon suggest that if it were somehow possible to distinguish this defective majority from the competent cells, then laboratory tests would become far more effective at predicting fertility outcomes.

\section{References}

Abaigar T, Holt WV, Harrison RAP \& del Barrio G 1999 Sperm subpopulations in boar (Sus scrofa) and gazelle (Gazella dama mhorr) semen as revealed by pattern analysis of computer-assisted motility assessments. Biology of Reproduction $6032-41$.

Abaigar T, Cano M, Pickard AR \& Holt WV 2001 Use of computerassisted sperm motility assessment and multivariate pattern analysis to characterize ejaculate quality in Mohor gazelles (Gazella dama mhorr): effects of body weight, electroejaculation technique and short-term semen storage. Reproduction 122 265-273.

Aitken RJ, Bowie H, Buckingham D, Harkiss D, Richardson DW \& West KM 1992 Sperm penetration into a hyaluronic acid polymer as a means of monitoring functional competence. Journal of Andrology 13 44-54.

Bahat A, Tur-Kaspa I, Gakamsky A, Giojalas LC, Breitbart H \& Eisenbach M 2003 Thermotaxis of mammalian sperm cells: a potential navigation mechanism in the female genital tract. Nature Medicine 9 149-150.

Beatty RA, Bennett GH, Hall JG, Hancock JL \& Stewart DL 1969 An experiment with heterospermic insemination in cattle. Journal of Reproduction and Fertility 19 491-502.

Berger T, Anderson DL \& Penedo MCT 1996 Porcine sperm fertilizing potential in relationship to sperm functional capacities. Animal Reproduction Science 44 231-239.

Birkhead TR \& Moller AP 1993 Sexual selection and the temporal separation of reproductive events: sperm storage data from reptiles, birds and mammals. Biological Journal of the Linnean Society $\mathbf{5 0}$ 295-311.

Birkhead TR \& Pizzari T 2002 Postcopulatory sexual selection. Nature Reviews Genetics 3 262-273.

Birkhead TR, Møller AP \& Sutherland WJ 1993 Why do females make it so difficult for males to fertilize their eggs? Journal of Theoretical Biology 161 51-60.

Cohen J 1969 Why so many sperm? An essay on the arithmetic of reproduction. Scientific Progress 57 23-41.
Cook SP, Brokaw CJ, Muller CH \& Babcock DF 1994 Sperm chemotaxis: egg peptides control cytosolic calcium to regulate flagellar responses. Developmental Biology 165 10-19.

Cox JF, Zavala A, Saravia F, Rivas C, Gallardo P \& Alfaro V 2002 Differences in sperm migration through cervical mucus in vitro relates to sperm colonization of the oviduct and fertilizing ability in goats. Theriogenology 58 9-18.

Creech MM, Arnold EV, Boyle B, Muzinich MC, Montville C, Bohle DS \& Atherton RW 1998 Sperm motility enhancement by nitric oxide produced by the oocytes of fathead minnows Pimephelas promelas. Journal of Andrology 19 667-674.

Curtsinger JW 1991 Sperm competition and the evolution of multiple mating. American Naturalist 138 93-102.

Dziuk PJ 1996 Factors that influence the proportion of offspring sired by a male following heterospermic insemination. Animal Reproduction Science $\mathbf{4 3}$ 65-88.

Eisenbach M 1999 Mammalian sperm chemotaxis and its association with capacitation. Developmental Genetics 25 87-94.

Fabro G, Rovasio RA, Civalero S, Frenkel A, Caplan SR, Eisenbach M \& Giojalas LC 2002 Chemotaxis of capacitated rabbit spermatozoa to follicular fluid revealed by a novel directionality-based assay. Biology of Reproduction 67 1565-1571.

Fazeli A, Duncan AE, Watson PF \& Holt WV 1999 Sperm-oviduct interaction: induction of capacitation and preferential binding of uncapacitated spermatozoa to oviductal epithelial cells in porcine species. Biology of Reproduction 60 879-886.

Fraga CG, Motchnik PA, Wyrobek AJ, Rempel DM \& Ames BN 1996 Smoking and low antioxidant levels increase oxidative damage to sperm DNA. Mutation Research 351 199-203.

Girardet A, McPeek MS, Leeflang EP, Munier F, Arnheim N, Claustres M \& Pellestor F 2000 Meiotic segregation analysis of RB1 alleles in retinoblastoma pedigrees by use of single-sperm typing. American Journal of Human Genetics 66 167-175.

Gomendio M \& Roldan ERS 1991 Sperm competition influences sperm size in mammals. Proceedings of the Royal Society of London. Series B Biological Sciences 243 181-185.

Hagaman JR, Moyer JS, Bachman ES, Sibony M, Magyar PL, Welch JE, Smithies O, Krege JH \& O'Brien DA 1998 Angiotensin-converting enzyme and male fertility. PNAS 95 2552-2557.

Harcourt AH, Harvey PH, Larson SG \& Short RV 1981 Testis weight, body weight and breeding system in primates. Nature 293 55-57.

Harrison RA 1998 Sperm evaluation: what should we be testing? In The 6th MAFF International Workshop on Genetic Resources. Genetic Diversity and Conservation of Animal Genetic Resources, pp 135-154. Tsukuba, Ibaraki, Japan: National Institute of Agrobiological Resources.

Harrison RAP \& Holt WV 2000 Modelling boar sperm signalling systems. In Boar Semen Preservation, Vol IV, pp 13-19. Eds LA Johnson \& HD Guthrie. Lawrence, KS: Allen Press Inc.

Harvey PH \& Bennett PM 1985 Sexual dimorphism and reproductive strategies. In Human Sexual Dimorphism, pp 43-59. Eds J Ghesquire, RD Martin \& F Newcombe. London: Taylor and Francis.

Hasselquist D, Bensch S \& von Schantz T 1996 Correlation between male song repertoire, extra-pair paternity and offspring survival in the great reed warbler. Nature 381 229-232.

Herrmann BG, Koschorz B, Wertz K, McLaughlin KJ \& Kispert A 1999 A protein kinase encoded by the $t$ complex responder gene causes non-Mendelian inheritance. Nature 402 141-146.

Holt WV \& Harrison RA 2002 Bicarbonate stimulation of boar sperm motility via a protein kinase A-dependent pathway: between-cell and between-ejaculate differences are not due to deficiencies in protein kinase A activation. Journal of Andrology 23 557-565.

Hunter RH \& Rodriguez-Martinez H 2004 Capacitation of mammalian spermatozoa in vivo, with a specific focus on events in the Fallopian tubes. Molecular Reproduction and Development 67 243-250.

Iwamatsu T, Onitake K, Matsuyama K, Satoh M \& Yukawa S 1997 Effect of micropylar morphology and size on rapid sperm entry into the eggs of the medaka. Zoological Science 14 623-628. 
Keller L \& Reeve HK 1995 Why do females mate with multiple males? The sexually selected sperm hypothesis. Advances in Animal Behaviour 24 291-315.

Kempenaers B, Verheyen GR, van der Broeck M, Burke T, van Broeckhoven C \& Dhondt AA 1992 Extra-pair paternity results from female preference for high quality males in the blue tit. Nature 357 494-496.

Kime DE, Van Look KJW, McAllister BG, Huyskens G, Rurangwa E \& Ollevier F 2001 Computer-assisted sperm analysis (CASA) as a tool for monitoring sperm quality in fish. Comparative Biochemistry and Physiology, C Toxicology and Pharmacology 130 425-433.

Kopeika J, Kopeika E, Zhang T, Rawson DM \& Holt WV 2003 Detrimental effects of cryopreservation of loach (Misgurnus fossilis) sperm on subsequent embryo development are reversed by incubating fertilised eggs in caffeine. Cryobiology 46 43-52.

Larson-Cook KL, Brannian JD, Hansen KA, Kasperson KM, Aamold ET \& Evenson DP 2003 Relationship between the outcomes of assisted reproductive techniques and sperm DNA fragmentation as measured by the sperm chromatin structure assay. Fertility and Sterility 80 895-902.

Linhart O, Kudo S, Billard R, Slechta V \& Mikodina EV 1995 Morphology, composition and fertilization of carp eggs: a review. Aquaculture 129 75-93.

Madsen T, Shine R, Loman J \& Hakansson T 1992 Why do female adders copulate so frequently? Nature 355 440-441.

Olds-Clarke P \& Johnson LR 1993 T-haplotypes in the mouse compromise sperm flagellar function. Developmental Biology 155 $14-25$.

Palumbi SR 1999 All males are not created equal: fertility differences depend on gamete recognition polymorphisms in sea urchins. PNAS $9612632-12637$.

Parker GA 1970 Sperm competition and its evolutionary consequences in the insects. Biological Reviews 45 525-567.

Parker GA 1998 Sperm competition and the evolution of ejaculates: towards a theory base. In Sperm Competition and Sexual Selection, pp 3-54. Eds TR Birkhead \& AP Moller. London: Academic Press.

Parrish JJ \& Foote RH 1985 Fertility differences among male rabbits determined by heterospermic insemination of fluorochromelabeled spermatozoa. Biology of Reproduction 33 940-949.

Petrie M \& Kempenaers B 1998 Extra-pair paternity in birds: explaining variation between species and populations. Trends in Ecology and Evolution $1352-58$

Pizzari T \& Birkhead TR 2002 The sexually-selected sperm hypothesis: sex-biased inheritance and sexual antagonism. Biological Reviews 77 183-209.

Ridley M 1993 Clutch size and mating frequency in parasitic Hymenoptera. American Naturalist 142 893-910.

Roldan ERS \& Gomendio M 1999 The Y-chromosome as a battle ground for sexual selection. Trends in Ecology and Evolution 14 $58-62$.
Smith TT \& Yanagimachi R 1991 Attachment and release of spermatozoa from the caudal isthmus of the hamster oviduct. Journal of Reproduction and Fertility 91 567-573.

Stahlberg R, Harlizius B, Weitze KF \& Waberski D 2000 Identification of embryo paternity using polymorphic DNA markers to assess fertilizing capacity of spermatozoa after heterospermic insemination in boars. Theriogenology 53 1365-1373.

Stewart DL, Spooner RL, Bennett GH, Beatty RA \& Hancock JL 1974 A second experiment with heterospermic insemination in cattle. Journal of Reproduction and Fertility 36 107-116.

Stockley P, Gage MJG, Parker GA \& Moller AP 1997 Sperm competition in fishes: the evolution of testis size and ejaculate characteristics. American Naturalist 149 933-954.

Swanson WJ \& Vacquier VD 2002 The rapid evolution of reproductive proteins. Nature Reviews Genetics 3 137-144.

Taborsky M 1998 Sperm competition in fish: 'bourgois' males and parasitic spawners. Trends in Ecology and Evolution 13 222-227.

Tajima Y, Okamura N \& Sugita Y 1987 The activating effects of bicarbonate on sperm motility and respiration at ejaculation. Biochimica et Biophysica Acta 924 519-529.

Van Look KJW \& Kime DE 2003 Automated sperm morphology analysis in fishes: the effect of mercury on goldfish sperm. Journal of Fish Biology 63 1020-1033.

Wakimoto BT 1979 DNA synthesis after polyspermic fertilization in the axolotl. Journal of Embryology and Experimental Morphology 52 39-48.

Ward GE, Brokaw CJ, Garbers DL \& Vacquier VD 1985 Chemotaxis of Arbacia punctulata spermatozoa to resact, a peptide from the egg jelly layer. Journal of Cell Biology 101 2324-2329.

Watson PJ 1991 Multiple paternity as genetic bet-hedging in female sierra dome spiders, Linyphia litigosa (Linyphiidae). Animal Behaviour 41 343-360.

Watson PJ 1998 Multi-male mating and female choice increase offspring growth in the spider Neriene litigiosa (Linyphiidae). Animal Behaviour 55 387-403.

WHO 1992 WHO Laboratory Manual for the Examination of Human Semen and Sperm-Cervical Mucus Interaction. Cambridge: Cambridge University Press.

Wood CD, Darszon A \& Whitaker M 2003 Speract induces calcium oscillations in the sperm tail. Journal of Cell Biology $\mathbf{1 6 1}$ 89-101.

Yasui Y 1997 A 'good sperm' model can explain the evolution of costly multiple mating by females. American Naturalist 149 573-584.

Yu S, Kojima N, Hakomori S-I, Kudo S, Inoue S \& Inoue Y 2002 Binding of rainbow trout sperm to egg is mediated by strong carbohydrate-to-carbohydrate interaction between (KDN) GM3 (deaminated neuraminyl ganglioside) and Gg3-like epitope. PNAS 99 $2854-2859$

Zeh JA \& Zeh DW 2001 Reproductive mode and the genetic benefits of polyandry. Animal Behaviour 61 1051-1063. 